\title{
A Smart Helmet-Based PLS-BPNN Error Compensation Model for Infrared Body Temperature Measurement of Construction Workers during COVID-19
}

\author{
$\operatorname{Li~Li}^{1}{ }^{1}$, Jiahui Yu ${ }^{1}$, Hang Cheng ${ }^{2}$ and Miaojuan Peng ${ }^{1, *}$ \\ 1 School of Mechanics and Engineering Science, Shanghai University, Shanghai 200044, China; \\ lilishu@shu.edu.cn (L.L.); 19723402@shu.edu.cn (J.Y.) \\ 2 School of Communication \& Information Engineering, Shanghai University, Shanghai 200044, China; \\ ch20721335@shu.edu.cn \\ * Correspondence: mjpeng@shu.edu.cn
}

Citation: Li, L.; Yu, J.; Cheng, H.; Peng, M. A Smart Helmet-Based PLS-BPNN Error Compensation Model for Infrared Body Temperature Measurement of Construction Workers during COVID-19. Mathematics 2021, 9, 2808. https:/ / doi.org/10.3390/math9212808

Academic Editor: Ivan Ganchev

Received: 17 September 2021

Accepted: 29 October 2021

Published: 5 November 2021

Publisher's Note: MDPI stays neutral with regard to jurisdictional claims in published maps and institutional affiliations.

Copyright: (c) 2021 by the authors. Licensee MDPI, Basel, Switzerland. This article is an open access article distributed under the terms and conditions of the Creative Commons Attribution (CC BY) license (https:/ / creativecommons.org/licenses/by/ $4.0 /)$.

\begin{abstract}
In the context of the long-term coexistence between COVID-19 and human society, the implementation of personnel health monitoring in construction sites has become one of the urgent needs of current construction management. The installation of infrared temperature sensors on the helmets required to be worn by construction personnel to track and monitor their body temperature has become a relatively inexpensive and reliable means of epidemic prevention and control, but the accuracy of measuring body temperature has always been a problem. This study developed a smart helmet equipped with an infrared temperature sensor and conducted a simulated construction experiment to collect data of temperature and its influencing factors in indoor and outdoor construction operation environments. Then, a Partial Least Square-Back Propagation Neural Network (PLS-BPNN) temperature error compensation model was established to correct the temperature measurement results of the smart helmet. The temperature compensation effects of different models were also compared, including PLS-BPNN with Least Square Regression (LSR), Partial Least Square Regression (PLSR), and single Back Propagation Neural Network (BPNN) models. The results showed that the PLS-BPNN model had higher accuracy and reliability, and the determination coefficient of the model was 0.99377. After using PLS-BPNN model for compensation, the relative average error of infrared body temperature was reduced by $2.745^{\circ} \mathrm{C}$ and RMSE was reduced by 0.9849 . The relative error range of infrared body temperature detection was only $0.005 \sim 0.143^{\circ} \mathrm{C}$.
\end{abstract}

Keywords: personnel health monitoring; construction site management; smart helmet; infrared temperature measurement; temperature error compensation; BP neural network; COVID-19

\section{Introduction}

The emergence and spread of "COVID-19" around the world has brought new challenges to construction site management. Building construction sites are usually areas where people gather and are highly mobile. Under the strict epidemic prevention and control policy, once an infected person appears in the workplace, if not detected in time, it will not only affect the construction progress of the whole project, but also cause serious social hazards. COVID-19 is an acute respiratory infectious disease caused by SARS-COV-2 virus infection. Among the ascertained symptoms related to SARS-Cov-2 infection, there is an alteration of body temperature [1]. Initial screening of febrile individuals can be effective in preventing the spread of the virus [2-4]. Therefore, the real-time monitoring of the temperature of construction personnel has become one of the necessary options in current construction site management. At present, the body temperature monitoring of construction personnel mostly utilizes handheld temperature guns or fixed infrared thermometers [5], but these methods cannot achieve real-time monitoring and the tracking of body temperature. The use of wearable devices with temperature measurement function in construction personnel 
management is a feasible solution for real-time body temperature monitoring, and smart helmets equipped with infrared temperature sensors are an ideal carrier. A smart helmet is a head-mounted intelligent device that combines Internet of things technology with an ordinary helmet to realize corresponding intelligent functions. Smart helmets are often used in industries such as counter-terrorism, fire protection, and mining [6-8]. In recent years, smart helmets used by construction workers have also emerged. Altamura [9] developed a smart helmet named SAFE that can be applied to construction sites. The smart helmet is equipped with a temperature sensor, heart rate sensor, and smoke detector, which can monitor the wearer's physical condition and surrounding environment in real time and transmit data to the server through Wi-Fi. The intelligent HeadgearX helmet developed by Aliyev [10] is equipped with ten kinds of sensors, including a smoke sensor, environmental light sensor, and atmospheric sensor, and can communicate with mobile phone through Bluetooth. The matching Android application is also developed to add more functions, including those configurable air functions. Building project managers can monitor the real-time status of all site personnel from a central Web server. Such research provides direction and reference for the application of smart helmets in construction sites. Safety helmets are necessary protective equipment for construction workers. If safety helmet is used as the carrier of infrared temperature measurement module, it will not add additional burden to workers while monitoring their temperature in real-time. However, the goal of applying smart helmets for epidemic prevention and control in construction sites also puts forward more requirements for the accuracy of temperature monitoring.

In recent years, non-contact infrared temperature-sensing technology has developed rapidly, which has the characteristics of fast measurement speeds and high sensitivity. However, in the actual measurement, the accuracy of infrared temperature measurement is easily affected by the measurement distance, ambient temperature, emissivity of the measured object surface, and other factors. Therefore, there may be a large error between the temperature of the human epidermis (forehead, arm, etc.,) obtained by infrared thermometry and the basal body temperature in a general monitoring environment [11,12]. This leads to the common problems of low measurement accuracy and large measurement errors in body temperature measurement using infrared thermometry sensors. A number of studies have been carried out to improve the accuracy of infrared thermometry in measuring human body temperature. Overall, these studies can be divided into two categories:

The first category involves empirical regression models by studying the error relationship between body temperature measurements and true values. Xu, K. [13] proposed a multiple linear regression method to establish an infrared temperature measurement error compensation model to improve the measurement accuracy, but the physical meaning of the model was not clear enough, and the factors affecting the accuracy were not sufficiently considered. When the temperature measurement environment changed, the model could not accurately predict the actual temperature of the human body. Guo, Z. [14] proposed a nonlinear cubic polynomial fitting temperature compensation algorithm to address the shortcomings of the linear compensation model. The accuracy of this algorithm was improved by about 2.25 times compared to the linear model, but the error was still too large for the accuracy requirements of body temperature measurement.

The second category established theoretical models between body temperature measurements and influencing factors through theoretical analysis and experiments. Wei, S. L. [15] established an infrared incidence angle compensation algorithm based on Stefan's law to reduce the temperature measurement error caused by the variation of infrared incidence angle through the study and analysis of the measured data. However, this model did not consider the influence of other factors and was difficult to apply practically. Shajkofeci, A. [16] collected 19,392 sets of measurement data sets, and used the same precision infrared sensors at different locations while tracking outside temperature, room temperature, and time of measurement. On this basis, the relationship between outside, ambient temperatures, hours in the day, and the measured forehead temperature's first and second degrees of polynomials were established. Using these models, the influence of external disturbance on tempera- 
ture measurement accuracy can be reduced. Although this method can greatly reduce the collinearity between these influence factors, the method of modeling separately may ignore the relationship between each influence factor.

In comparison, the first type of method is more practical, but a large amount of experimental data is required for model building. The experimental process of the second type of method is easy to control, but it is difficult to comprehensively consider various factors that affect the temperature measurement accuracy. Therefore, there were also studies that fused the two ideas and proposed a calibration algorithm that combines theory and experience. Based on the blackbody thermal radiation principle, AI, H. [17] converted the infrared signal into Celsius temperature signal through the correction look-up table method and applied the twice linear regression algorithm to establish an error compensation model for in-ear cavity infrared thermometry, considering the effect of ambient temperature, and obtained the model parameters through the blackbody standard experiment. The results showed that the temperature error in the range of $35 \sim 42{ }^{\circ} \mathrm{C}$ remains within \pm 0.2 after using the model. Pan [18] proposed a nonlinear polynomial regression model to compensate for the measurement error caused by dust and measurement distance. The results showed that the model can significantly reduce the measurement error caused by these two factors, but did not help with the other influencing factors.

In general, a lot of progress has been made in the research of error compensation for infrared temperature measurement, which has created a good foundation for practical engineering applications. However, in different application scenarios, the causes of infrared temperature measurement error are not the same. When infrared temperature measurement technology is used in a smart helmet, the possible causes of measurement error include: (i) The influence of the wearer's environment on skin temperature; (ii) The influence of the sensor's environment on measurement accuracy; (iii) The influence of the wearer's sweat on skin reflectivity; (iv) The vaporization of the wearer's sweat leads to the reduction of skin temperature. These influences are related to a variety of factors. Therefore, in order to improve the measurement accuracy, the compensation calculation of the measurement error needs to fully consider the helmet-wearing environment and its contact with the human body.

The aim of this study is to comprehensively analyze the factors affecting the accuracy of the measured personnel's forehead epidermal temperature measurement and to establish a high-precision temperature measurement model, so as to reduce the misjudgment of the construction personnel's physical condition. Therefore, a smart helmet is developed in this study, which can not only monitor the wearer's temperature, but also obtain the temperature and humidity data inside the helmet. During the experiment, the wearer's real body temperature, ambient temperature and humidity, and ambient wind speed were collected. By analyzing the relationship between these environmental variables and temperature measurement error, the influence of the above factors on the temperature measurement accuracy of the smart helmet was quantified. Considering the multicollinearity of environmental variables and the nonlinear relationship between environmental variables and temperature measurement error, a modeling method combining multivariate statistical analysis theory and a neural network is proposed in this study, which can effectively improve the accuracy of the temperature measurement error compensation model.

Since the use of smart helmets for project management and personnel health monitoring in the actual construction environment is still an emerging technical tool, and its measurement precision largely affects the application and popularization of the smart helmet, the research in this study has important social significance and practical value in the context of a current human society that will coexist with the "COVID-19" epidemic for a long time. 


\section{Smart Helmet Development and Data Collection}

\subsection{Smart Helmet Temperature Measurement System}

This study utilizes a smart helmet equipped with an infrared temperature sensor to continuously monitor and track the body temperature of personnel to obtain actual temperature data. The smart helmet is self-developed. In order to guarantee continuous data acquisition and communication, and to consider the subsequent temperature data correction needs, the smart helmet measurement system also includes a Temperature/Humidity $(\mathrm{T} / \mathrm{H})$ sensor for collecting the temperature and humidity inside the helmet, a $4 \mathrm{G}$ communication module for data transmission, a microprocessor for the control system, a digital display for data reading, and a rechargeable power supply module. The system is arranged as shown in Figure 1.

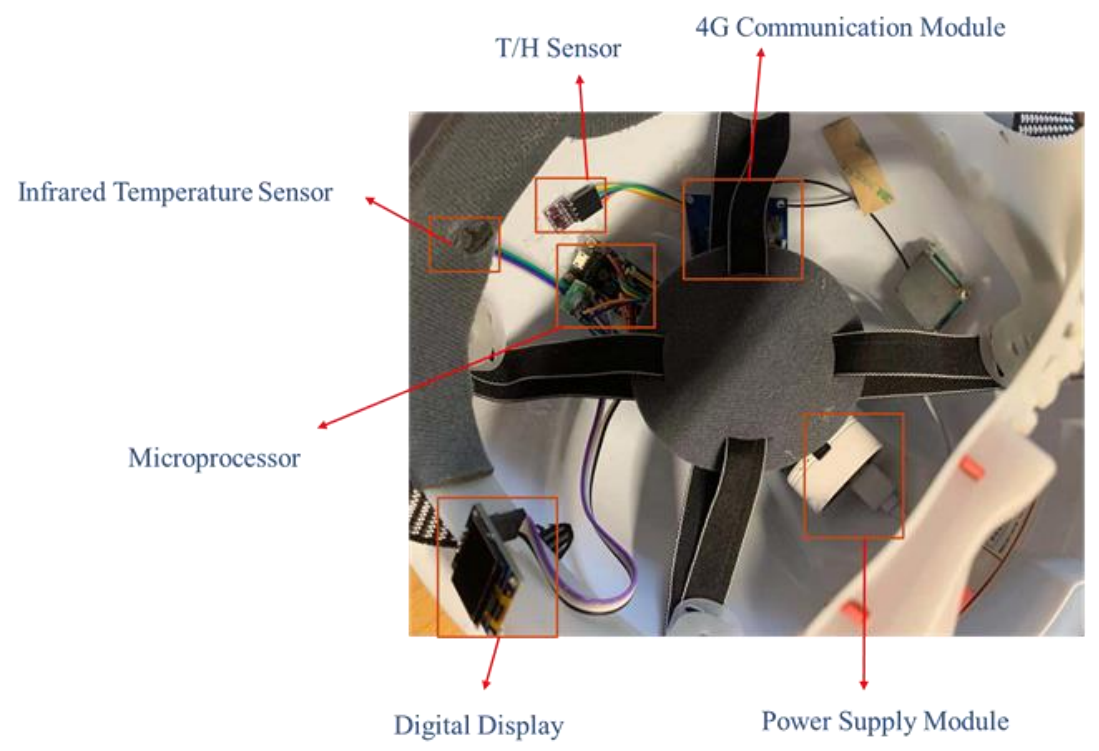

Figure 1. Structure of smart helmet system.

The $\mathrm{T} / \mathrm{H}$ sensor is placed inside the helmet to collect real-time temperature and humidity data during the wearing process to support the subsequent temperature data correction. The infrared temperature sensor is placed on the contact point between the helmet liner and the human forehead to collect the infrared signal from the human forehead skin. Although in practical applications a temperature measurement accuracy of $0.1{ }^{\circ} \mathrm{C}$ is enough, higher measurement accuracy and resolution can bring more information, which helps to improve the application effect of the model. The infrared temperature sensor model used in this study is MLX90614ESF, and the measurement resolution of the sensor is $0.01{ }^{\circ} \mathrm{C}$ (measurement accuracy is $0.05^{\circ} \mathrm{C}$ ). The infrared signal collected by the infrared temperature sensor is transmitted to the microprocessor for processing after a series of amplification and filtering, and the temperature data of the human forehead skin is outputted. The smart helmet measurement process is shown in Figure 2.

Endurance capability is an issue that must be considered for Internet of things equipment. In order to reduce power consumption, the helmet adopts an STM32F411 microprocessor and carries out a low power consumption design. The average operating current of the microprocessor is $5.4 \mathrm{~mA}$. The wireless communication module adopts a Quectel EC20 communication module, with an average operating current of $6.1 \mathrm{~mA}$ (data transmission every $10,000 \mathrm{~ms}$ ). The total operating current of the smart helmet is $26.8 \mathrm{~mA}$, and it is powered by a rechargeable lithium battery with a capacity of $3200 \mathrm{mAh}$, which can last up to $120 \mathrm{~h}$. 


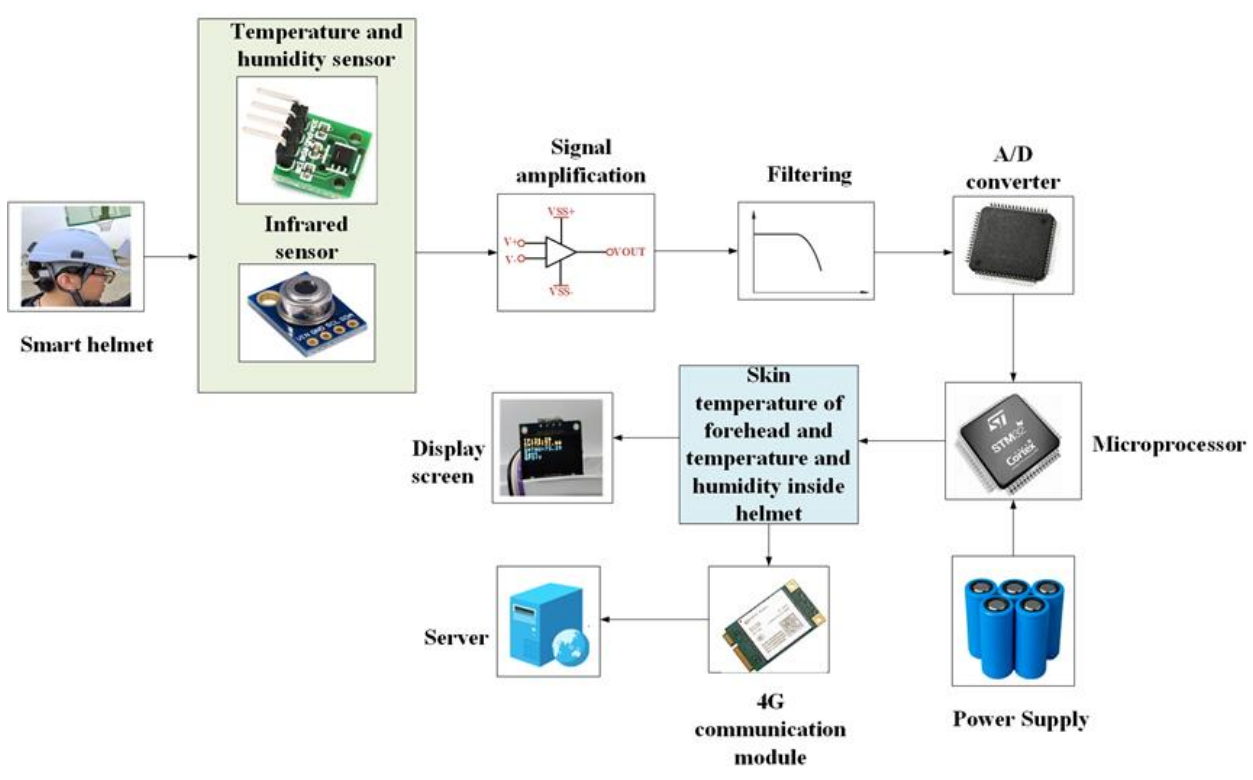

Figure 2. The smart helmet measurement process.

\subsection{Influence Factors of Temperature Measurement Error}

According to Kirchhoff's Law and Stefan-Boltzmann Law, the relation between the radiation energy, density, and temperature on the surface of an object complies with Equation (1):

$$
\mathrm{M}=\varepsilon \sigma \mathrm{T}^{4}
$$

where, $\mathrm{M}$ is the radiation emission $\left(\mathrm{J} /\left(\mathrm{s} \cdot \mathrm{m}^{2}\right)\right)$, that is, the radiation power emitted per unit area, $\varepsilon$ is the emissivity of the object, $\sigma$ is Stephan-Boltzmann constant, $\mathrm{T}$ is the thermodynamic temperature of the body (K). It can be seen from Equation (1) that, if the radiation emission of an object is measured, the temperature of the object can be determined, which is the theoretical basis for infrared temperature measurement [19]. Therefore, the factors affecting the accuracy of infrared temperature measurement can be determined by analyzing the factors affecting the radiation emissivity.

The radiation received by the infrared sensor is mainly divided into three parts: radiation from the target, reflected radiation from the environment, and radiation from the atmosphere [20]. In other words, the temperature measured by the infrared temperature sensor includes the interference of various kinds of radiation in the measurement environment. The environment reflection radiation mainly related to the temperature and humidity of the environment in which the infrared sensor is located.

As the smart helmet is worn on the head, the temperature sensor location is close to the forehead, so that the effect of atmospheric transmittance is almost negligible. At the same time, since the construction workers may sweat a lot during the construction operation, and the sweat will interfere with the measurement accuracy of the infrared sensor, this study quantifies this factor by measuring the humidity inside the helmet. Besides, there is convective heat exchange between the human forehead surface and the outside air, and when the heat dissipation is high, the forehead temperature will drop, thus deviating from the true body temperature. The convective heat transfer coefficient is related to the wind speed in the environment, which means that the wind speed affects the measurement error of the infrared temperature sensor [21].

In order to quantify the degree of influence of the environmental factors on the infrared temperature measurement of smart helmets, the indicators selected for measurement and analysis in this study include ambient temperature (AT), ambient humidity (AH), temperature inside helmet (TI), humidity inside helmet (HI), and wind speed (WP). 


\subsection{Smart Helmet Temperature Measurement Experiment}

In order to explore the degree of influence of environmental factors on the infrared temperature measurement of the smart helmet, and to establish a temperature error compensation model, this study conducted several groups of indoor and outdoor experiments to simulate the scenes of construction workers in indoor and outdoor construction operations, respectively. During the experiments, the temperature of the human forehead epidermis and the temperature and humidity inside the helmet were collected using the smart helmet, and the temperature inside the ear was measured using an ear temperature gun as the true value of body temperature [22]. Meanwhile, a thermometer, hygrometer, and anemometer were used to measure the external ambient temperature, humidity, and wind speed.

In order to simulate the working hours of a construction site, the experiment was conducted from 8:00 to 12:00 and 14:00 to 18:00. The experiment was carried out in groups of two persons each. One person wore a helmet to simulate the general labor intensity of construction and performed simple movements in the defined site, while the other person was responsible for reading and recording data from the display (Figure 3) on the helmet on time and was called the recorder.

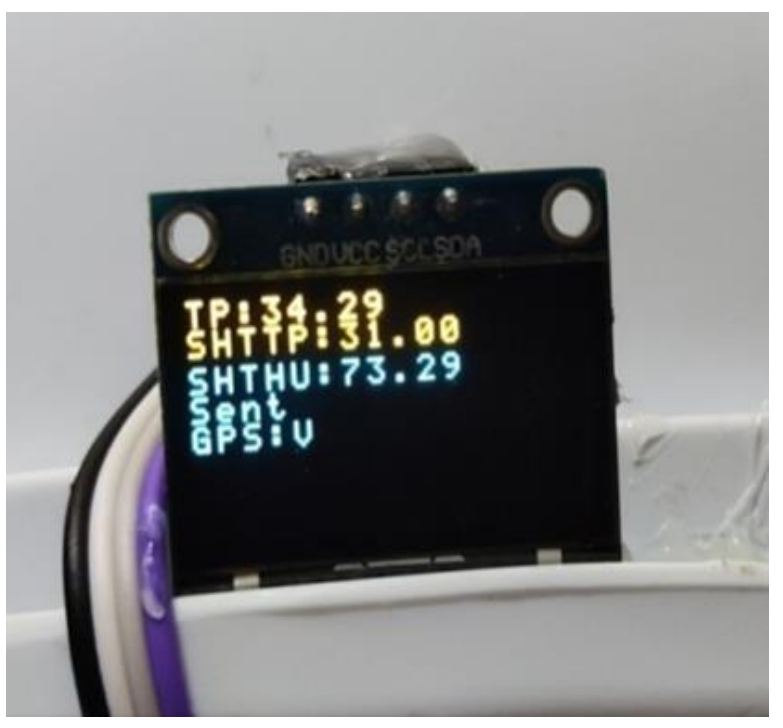

Figure 3. Display on smart helmet.

There were three key datasets on the display. TP represented the body temperature value collected by the infrared sensor on the smart helmet. SHTTP and SHTHU were the temperature and humidity inside the helmet, respectively. The specific experimental steps were as follows:

1. The experimenter wore a smart helmet and held a digital anemometer. The experimenter pressed the storage function of the digital anemometer to save the real-time ambient wind speed (Figure 4).

2. The experimenter used the ear temperature gun to measure his or her ear canal temperature, and then the recorder took a reading and recorded the value.

3. At the same time, the recorder quickly recorded the measured temperature displayed on the helmet, the temperature and humidity inside helmet, the wind speed displayed on the anemometer, and the ambient temperature and humidity displayed on the ambient thermometer and hygrometer.

4. In each recording, the true body temperature was recorded once. The helmetmeasured temperature was recorded three times as measured temperature 1, measured temperature 2 , and measured temperature 3 . The average value was taken as the final measured temperature (MT) of the infrared temperature sensor to reduce the 
random error. The difference between the measured temperature and the true body temperature was recorded as the temperature error.

5. The above steps were repeated, and data were recorded every $5 \mathrm{~min}$. Each experiment lasted for $4 \mathrm{~h}$. During the experiment, the experimenter was required to continuously walk around appropriately and wear the smart helmet continuously without removing the helmet until the end of the experiment. In order to simulate the different environments of indoor and outdoor construction, the experiment was divided into indoor and outdoor parts. The data categories and experiment durations were the same in both indoor and outdoor experiments for comparison purposes. The number of samples in each part was 245 sets, with a total of 490 sets. Figure 5 shows the distribution of the measured temperature and the true value of body temperature.

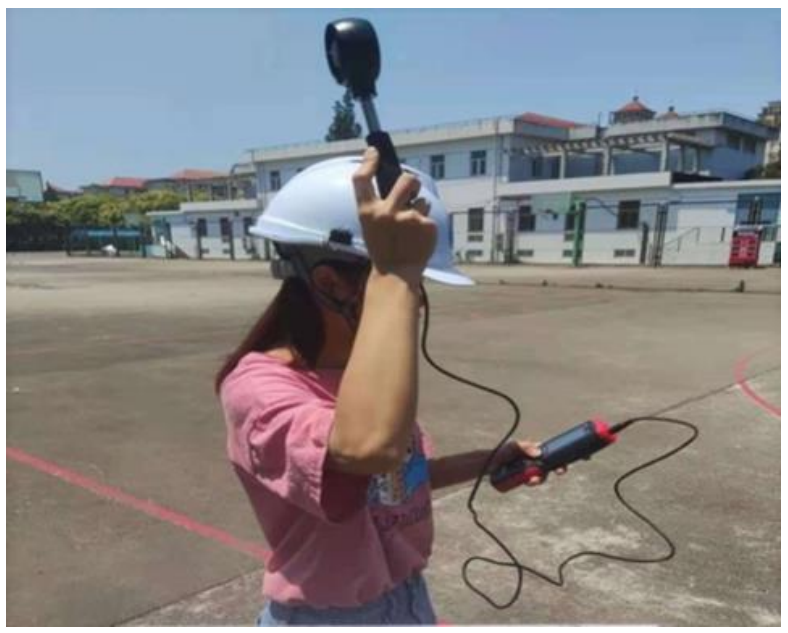

Figure 4. Experimenters measuring wind speed.

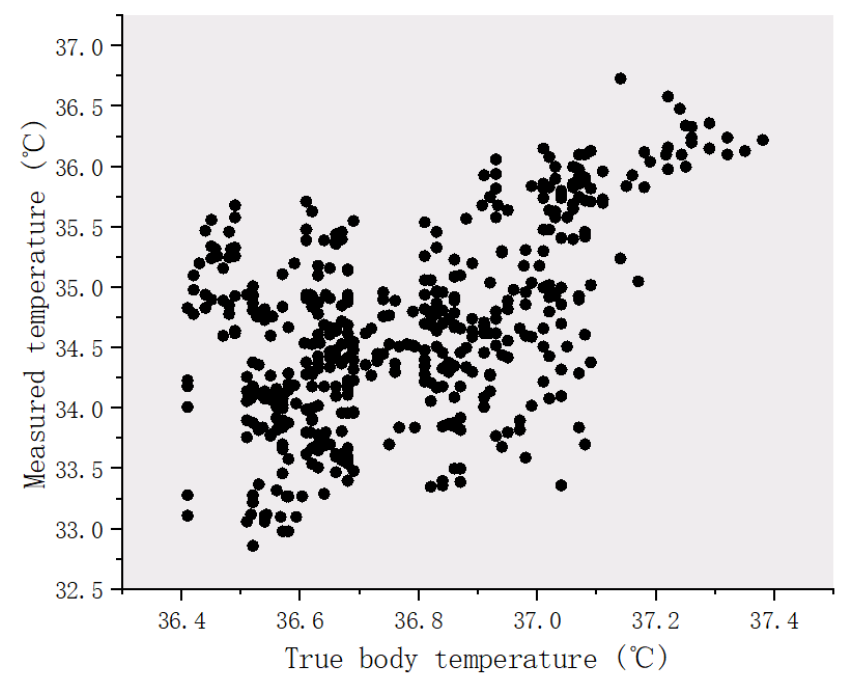

Figure 5. Scatter diagram of true body temperature and measured temperature.

As can be seen from Figure 5, the real body temperature is distributed between $36.4{ }^{\circ} \mathrm{C}$ and $37.5^{\circ} \mathrm{C}$, while the measured temperature is generally lower than the real temperature. The temperature data in this experiment can be considered to be in the normal range, as long-term physical activity leads to the rise of human body temperature, which may even exceed $38^{\circ} \mathrm{C}$ [23-25]. 


\section{Modeling and Data Analysis}

\subsection{Modeling Method}

The purpose of this study is to analyze the influence of various influencing factors on the error of infrared temperature measurement according to the experimental data, and to establish the error compensation model of infrared temperature measurement. In previous studies, regression analysis (such as multivariate linear regression [26-30], ridge regression $[31,32]$, and logistic regression $[33,34]$ ) is usually used to analyze the relationship between multiple factors and the establishment of a mathematical model. Moreover, the ordinary least square (OLS) method is the most widely-used parameter estimation method in regression analysis. Due to the multicollinearity problem among the factors influencing the temperature measurement error discussed in this study, this problem would have a great impact on the analysis results and even lead to model failure if the ordinary least square method was used for regression analysis [35]. In addition, since the infrared temperature measurement error was nonlinear, a simple linear processing cannot properly correct such errors [36].

To solve the above problems, it is necessary to find an analytical method that can overcome the problem of multicollinearity among the influencing factors. In previous studies, ridge regression, principal component regression, and partial least squares regression have achieved good results in overcoming the problem of multicollinearity [37-40]. Ridge regression is essentially an improved least squares estimation method. It is more practical to obtain the regression coefficient at the cost of losing some information and reducing accuracy by abandoning the unbiased nature of the least squares method. Therefore, compared with principal component regression and partial least squares regression, the regression coefficient of ridge regression model is higher, but the accuracy is lower [40]. Both partial least squares regression and principal component regression achieve the purpose of data dimensionality reduction by extracting principal components, and then overcome the influence of multicollinearity. Compared with the partial least square (PLS) method, although the principal component analysis (PCA) method can effectively simplify a highdimensional variable system into a low-dimensional variable system, and all variables in the new variable system are linearly independent, it cannot avoid the influence of overlapping information in the original variables [41]. This overlapping information may sometimes not have much explanatory significance for the dependent variable and thus become noise. As the PCA completely leaves out the dependent variables when extracting the principal components, the principal component may have a strong generalization ability to the independent variable system, but its explanatory ability to the dependent variables may become very weak. PLS absorbs the idea of extracting components from PCA and simplifies the data structure on the one hand, and is able to correlate the set of independent variables and the set of dependent variables on the other. That is, PLS considers both the generalization of the components to the independent variables and pays more attention to the explanatory significance of dependent variables [42]. Therefore, using PLS method to extract the principal components of data can overcome the problem of multicollinearity among influencing factors and effectively eliminate noise in the data. Therefore, in this study, PLS method was used to extract the principal components.

To solve the problem of low accuracy regarding the prediction results of fitting multidimensional, nonlinear function by conventional methods, an artificial neural network is widely used in fitting nonlinear function [43-45]. An artificial neural network has the ability to approximate any nonlinear continuous function with arbitrary accuracy, and back propagation (BP) neural networks have strong self-learning behavior, self-organization, and a nonlinear approximation function [46,47]. As long as the number of neurons is sufficient, a BP neural network can fit complex nonlinear functions with only a three-layer structure, which greatly reduces the complexity of the network [48]. It not only reduces the calculation time, but also ensures the accuracy of the model.

Therefore, in this study the principal components extracted by the PLS method were used as input variables and the temperature errors were used as output variables for BP 
neural network training, and, finally, the temperature error compensation model coupled with PLS and BP neural networks (PLS-BPNN) was established. This model can effectively reduce the prediction error brought by linear processing and solve the nonlinear problem of the temperature compensation model. Figure 6 shows the structure diagram of the PLS-BPNN coupling model.

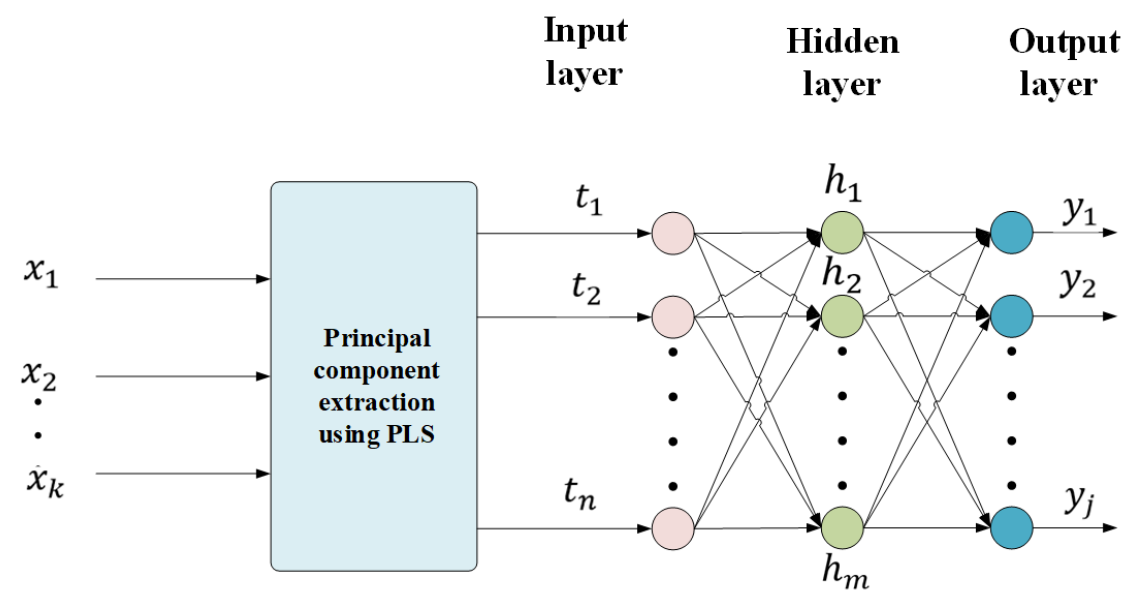

Figure 6. Structure diagram of the PLS-BPNN coupling model.

\subsection{Multicollinearity Analysis}

Multicollinearity is a statistical phenomenon in which predictor variables in a regression model are highly correlated [49]. It is a data problem which may cause serious difficulty with the reliability of the estimates of the model parameters [50]. Therefore, the influence of multicollinearity should be overcome. The influencing factors considered in this study may have multicollinearity, because there is a theoretical correlation between ambient temperature and ambient humidity, inside temperature and humidity, and ambient temperature and wind speed.

To verify this view, and to explore the correlation between ambient temperature (AT), ambient humidity $(\mathrm{AH})$, temperature inside helmet (TI), humidity inside helmet (HI), and wind speed (WP) and temperature error (TE), the correlation coefficient between them is calculated, and the results are shown in Figure 7.

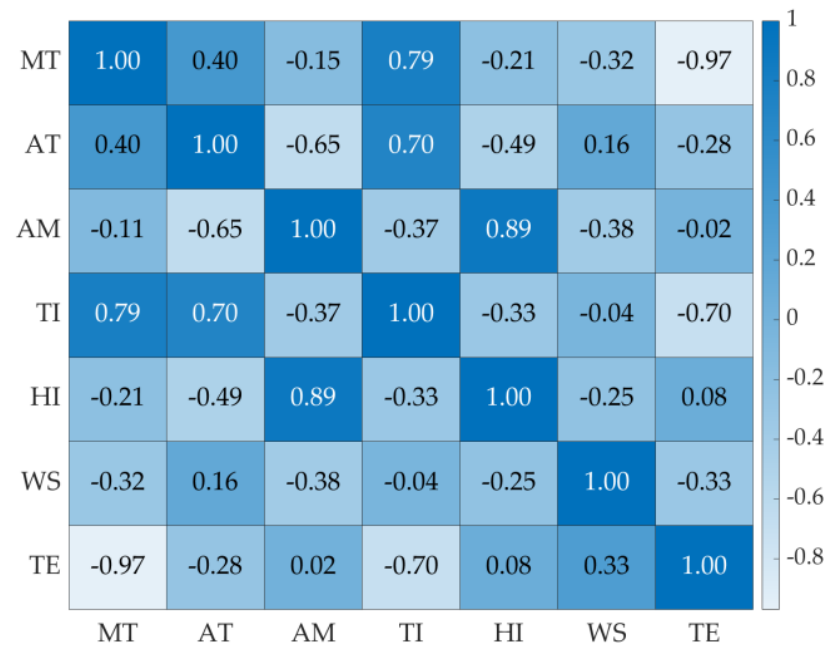

Figure 7. Correlation thermodynamic diagram.

The correlation thermodynamic diagram can clearly show the correlation between each variable. The scale on the right side of the thermodynamic diagram shows the color depth corresponding to different correlation coefficients. The color and corresponding number of 
each box represent the correlation coefficient between the two variables' corresponding to the box.

The correlation coefficient is the quantity of linear correlation between variables. There are many ways to define the correlation coefficient. The correlation coefficient used in this study is the most widely used Pearson correlation coefficient [51]. The Pearson correlation coefficients are between -1 and 1 , where a result close to 1 indicates that the two variables are positively correlated, a result close to -1 indicates that they are negatively correlated, and one closer to 0 indicates that they are not correlated.

As can be seen in Figure 7, there are multiple correlations between independent variables affecting the infrared temperature measurement of the helmet. For example, the correlation coefficient between the infrared measured temperature and temperature inside the helmet is 0.79 , and the correlation coefficient between the ambient temperature and the ambient humidity is -0.65 . To further verify and quantify the multicollinearity between independent variables, the variance inflation factor (VIF) diagnostic method and tolerance value were used in this study to determine the degree of multicollinearity [52]. The VIF and tolerance are both widely-used measures of the degree of multicollinearity of the ith independent variable with the other independent variables in a regression model. Not uncommonly, a VIF of 10 or even one as low as 4 (equivalent to a tolerance level of 0.10 or 0.25 ) have been used as a rule of thumb to indicate excessive or serious multicollinearity [53].

The expression of variance inflation factor is: $V I F_{i}=\left(1-R_{i}^{2}\right)^{-1}$. Where $R_{i}$ is $\mathrm{t}$ the complex correlation coefficient of the ith independent variable $\left(x_{i}\right)$ and other independent variables. The largest $(V I F)_{k}$ of all independent variables is often used to determine the degree of multicollinearity. As can be seen from Table 1, the variance inflation factors of three variables are greater than the critical value of 4 , among which the VIF value of ambient humidity is about 8.468 , which is the largest among the six variables.

Table 1. Results of covariance test for the influencing factors of infrared temperature measurement of smart helmets.

\begin{tabular}{ccc}
\hline Variable & Tolerance & VIF \\
\hline Measured temperature & 0.271 & 3.684 \\
Ambient temperature & 0.280 & 3.577 \\
Ambient humidity & 0.118 & 8.468 \\
Temperature inside helmet & 0.191 & 5.234 \\
Humidity inside helmet & 0.171 & 5.845 \\
Wind speed & 0.663 & 1.509 \\
\hline
\end{tabular}

\subsection{Extraction of Principal Components}

Therefore, this study next extracts the principal components of the independent and dependent variables using PLS. The analysis of the influencing factors shows that there are six possible factors affecting the infrared temperature measurement error, thus there are six independent variables, which are measured temperature $\left(x_{1}\right)$, ambient temperature $\left(x_{2}\right)$, ambient humidity $\left(x_{3}\right)$, temperature inside helmet $\left(x_{4}\right)$, humidity inside helmet $\left(x_{5}\right)$, and wind speed $\left(x_{6}\right)$, and the temperature error (y) to be compensated is the dependent variable. Thus, the 490 sets of experimental data were divided into two sets $\mathrm{X}=\left[x_{1}, x_{2}, x_{3}, x_{4}, x_{5}, x_{6}\right]_{490 \times 6}$ and $Y=[y]_{490 \times 1}$. In order to eliminate the influence of data dimensions, $X$ and $Y$ are normalized as $\mathrm{E}_{0}=\left[\mathrm{E}_{01}, \mathrm{E}_{02}, \mathrm{E}_{03}, \mathrm{E}_{4}, \mathrm{E}_{05}, \mathrm{E}_{06}\right]_{490 \times 6}$ and $\mathrm{F}_{0}=\left[\mathrm{F}_{0}\right]_{490 \times 1}$, respectively. Then, the first pair of principal components $t_{1}$ and $u_{1}$ of the two sets of variables can be extracted. According to the standardized observation data matrices $E_{0}$ and $F_{0}$ of the two sets of 
variable sets, the score vector of the first pair of components can be calculated and recorded as $\hat{t}_{1}$ and $\hat{u}_{1}$, as shown in Formula (2) and (3).

$$
\begin{aligned}
& \hat{t_{1}}=\mathrm{E}_{0} w_{1}=\left[\begin{array}{ccc}
x_{11} & \cdots & x_{16} \\
\vdots & \ddots & \vdots \\
x_{4901} & \cdots & x_{4906}
\end{array}\right]\left[\begin{array}{c}
w_{11} \\
\vdots \\
w_{16}
\end{array}\right]=\left[\begin{array}{c}
t_{11} \\
\vdots \\
t_{4901}
\end{array}\right] \\
& \hat{u}_{1}=\mathrm{E}_{0} v_{1}=\left[\begin{array}{c}
y_{1} \\
\vdots \\
y_{490}
\end{array}\right]\left[v_{1}\right]=\left[\begin{array}{c}
u_{11} \\
\vdots \\
u_{4901}
\end{array}\right]
\end{aligned}
$$

where $w_{1}$ and $v_{1}$ are the transformation matrices of the first pair of principal components.According to the principle of principal component analysis in PLS, in order to maximize the correlation between $t$ and $u$, that is, to maximize the covariance of $t$ and $u$, the covariance cov $\left(t_{1}, u_{1}\right)$ of the first pair of components $t_{1}$ and $u_{1}$ can be calculated by the inner product of the sum of the score vectors of the first pair of components. Therefore, the above requirements can be transformed into a mathematical conditional extreme value problem, as shown in Formula (4).

$$
\left\{\begin{array}{c}
\left\langle\hat{\mathrm{t}}_{1}, \hat{u}_{1}\right\rangle=w_{1}{ }^{T} \mathrm{E}_{0}{ }^{T} \mathrm{~F}_{0} v_{1} \Rightarrow \max \\
w_{1}{ }^{T} w=\left\|w_{1}\right\|^{2}=1, v_{1}{ }^{T} v=\left\|v_{1}\right\|^{2}=1
\end{array}\right.
$$

Using the Lagrange Multiplier method, the above problem can be transformed into finding the unit vectors $w_{1}$ and $v_{1}$, so that $\theta_{1}=w_{1}{ }^{T} \mathrm{E}_{0}{ }^{T} \mathrm{~F}_{0} v_{1} \Rightarrow \max$. Just by calculating the eigenvalues and eigenvectors of the $\mathrm{m}$ order matrix $\mathrm{M}=E_{0}{ }^{T} \mathrm{~F}_{0} F_{0}{ }^{T} E_{0}$, the maximum eigenvalue of $\mathrm{M}$ is $\theta_{1}^{2}$, the corresponding unit eigenvector is $w_{1}$, and the corresponding $v_{1}=\frac{w_{1}^{T} \mathrm{E}_{0}^{T} \mathrm{~F}_{0}}{\theta_{1}}$. The following results were obtained after calculation:

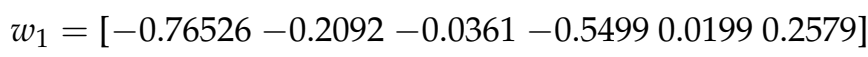

$$
\begin{aligned}
& v_{1}=1
\end{aligned}
$$

Then, substitute $w_{1}$ and $v_{1}$ into Formula (2) and (3) to calculate $t_{1}$ and $u_{1}$. The regression equations of $E_{0}$ about $t_{1}$ and $\mathrm{F}_{0}$ about $u_{1}$ are established respectively, $E_{0}=\hat{t_{1}} \alpha_{1}^{T}+E_{1}$, $F_{0}=\hat{u}_{1} \beta_{1}^{T}+F_{1}$, where $E_{1}$ and $F_{1}$ are residual matrix. After, replace the $E_{0}$ and $F_{0}$ with $E_{1}$ and $F_{1}$ respectively, repeat the above calculation, $t_{2}, t_{3} \cdots t_{r}$, and $u_{2}, u_{3} \cdots u_{r}$ can be calculated.

In general, PLS does not need to select all the existing components; however, like principal component analysis, only the first few components are selected. For the number of principal components to be extracted for modeling, the value can be determined by a cross validity test. Each time the ith sample is discarded, the remaining data samples are regressed by PLS method, and the regression equation fitted after extracting $h$ ( $h$ is the number of principal components extracted) principal components is established. Then, the ith sample discarded previously is substituted into this regression equation to obtain the predicted value of $y$ at the ith sample, which is denoted as $\hat{y}_{i}(h)$. Then, repeat the above steps for $i=1$ to 490 to obtain the Prediction Residual Error Sum of Squares (PRESS) of the dependent variable $y$ when $\mathrm{h}$ principal components are extracted, as shown in Formula (5). After that, all sample points are used to fit the regression equation with $h$ principal components, and the predicted value of ith sample is thus obtained, which is denoted as $\hat{y}_{-i}(h)$. Then, the SS (Error Sum of Squares) of $y$ can be calculated, as shown in Formula (6).

$$
\operatorname{PRESS}(h)=\sum_{i=1}^{490} y_{i}-\hat{y}_{i}(h)
$$




$$
S S(h)=\sum_{i=1}^{490} y_{-i}-\hat{y}_{-i}(h)
$$

Generally, when $Q_{h}=1-\frac{\operatorname{PRESS}(h)}{S S(h-1)}<0.0975$, it indicates that the insertion of the $h$ th new component has no significant improvement on the prediction ability of the model [54]. It is calculated that $Q_{h}<0.0975$ when $h=4$, therefore only three principal components need to be extracted in this study, and the expression is shown in Formula (7).

$$
\left[\begin{array}{l}
t_{1} \\
t_{2} \\
t_{3}
\end{array}\right]=\left[\begin{array}{cccccc}
-0.7653 & -0.2092-0.0361 & -0.5499 & 0.0199 & 0.2579 \\
-0.5475 & 0.5350-0.5133 & 0.0961 & -0.3589 & 0.1119 \\
-0.6450 & 0.4394 & 0.0354 & 0.2354 & 0.2023 & -0.5416
\end{array}\right] E_{0}{ }^{T}
$$

\subsection{Fitting by BP Neural Network Model}

Compared with the general neural network, a BP neural network can adjust the weights layer by layer, starting from the last layer, and the loss function is reduced to an acceptable range through multiple epochs [46]. The general form of weight adjustment in a neural network is $\Delta \mathrm{W}=\eta(X)^{T} \delta$. Where, $\eta$ is the learning rate, that is, the step size of weight adjustment, $X$ is the input matrix, $\delta$ is the learning signal, that is, the direction of each weight adjustment, which is actually a gradient vector [55].

Suppose an N-layer BP neural network, its last layer of learning signal can be described as $\delta^{n}=(t-y) f^{\prime}\left(X^{n} W^{n}\right)$, where $t$ is the expected output, $y$ is the model output, $f^{\prime}(x)$ is the derivative of the activation function, $X^{n}$ and $W^{n}$ are the input matrix and weight matrix of the nth layer, respectively. Moreover, the learning signal of other layers other than the last layer is $\delta^{i+1}=\delta^{i} W^{i} f^{\prime}\left(X^{i} W^{i}\right)$, where $i+1$ represents the layer after the $i$ th layer.

This study adopts a three-layer BP neural network model, including input layer, hidden layer and output layer. The input layer of the model is $X=\left[t_{1}, t_{2}, t_{3}\right]$, the output layer is $\mathrm{Z}=[\mathrm{Z}]$, and the expected output is $\mathrm{Y}=\mathrm{F}_{0}$. Assuming that the hidden layer has $m$ neurons, then the output matrix of the hidden layer is $H=\left[h_{1}, h_{2}, h_{3} \cdots h_{m}\right]$. The weight matrix from the input layer to the hidden layer is $\mathrm{V}=\left[\mathrm{v}_{1}, \mathrm{v}_{2}, \mathrm{v}_{3} \cdots \mathrm{v}_{\mathrm{j}} \cdots \mathrm{v}_{\mathrm{m}}\right]$, where $v_{j}$ represents the weight vector of the $j$ th neuron of the hidden layer. The weight matrix from the hidden layer to the output layer is $\mathrm{W}=[\mathrm{w}]$.

Due to the superposition of linear functions, no matter how many hidden layers are calculated, the final output results are linearly varied, that is, the whole model is linear. In order to remove the linearization of the whole neural network output and make the whole neural network model non-linear, the sigmoid function is adopted as the activation function in this study, as shown in Formula (8). Moreover, its derivative function is given in Formula (9). Sigmoid function is a bounded differentiable real function that is defined for all real input values and has a positive derivative at each point. It is often used as the activation function of neural network [56-58].

$$
\begin{gathered}
f(x)=\frac{1}{1-e^{x}} \\
f^{\prime}(x)=\frac{e^{-x}}{\left(1+e^{-x}\right)^{2}}
\end{gathered}
$$

Then, the output function of the output layer is $Z=f(S)$, where $S=\sum_{j=0}^{m} w_{j} h_{j}$, and the output function of the hidden layer is $\mathrm{h}_{j}=f\left(\mathrm{~S}_{j}\right)$, where $\mathrm{S}_{j}=\sum_{i=1}^{3} v_{i j} x_{i}$. Formula (10) gives the means to calculate the loss function used in this study. Where $n$ is the total number of training samples, $d(k)$ is the expected output of the corresponding input $x(i)$, and $z(k)$ is the actual output of the corresponding input $x(i)$. By substituting the output function of the output layer and the output function of the hidden layer into the loss function, it can be found that the loss function is a function of two weight matrices. In order to reduce 
the value of the loss function, the weight should be adjusted in the direction of negative gradient, as shown in Formula (11) and (12).

$$
\begin{gathered}
E=\frac{\sum_{k=1}^{n}(d(k)-z(k))^{2}}{n} \\
\Delta W_{j}=-\eta \frac{\partial E}{\partial w_{j}} \\
\Delta V_{i j}=-\eta \frac{\partial E}{\partial v_{i j}}
\end{gathered}
$$

where $\Delta W_{j}$ is the weight adjustment value from the jth neuron in the hidden layer to the output layer, and $\Delta V_{i j}$ is the weight adjustment value from the ith neuron in the input layer to the jth neuron in the hidden layer, after taking the derivative of the above formulae, the learning signals of the output layer and the hidden layer are defined as $\delta^{Z}=-\frac{\partial E}{\partial S}$ and $\delta_{j}^{H}=-\frac{\partial E}{\partial S_{j}}$. Then, the expression for $\Delta W_{j}$ and $\Delta V_{i j}$ is $\Delta W_{j}=-\eta \delta^{Z} h_{j}$ and $\Delta V_{i j}=-\eta \delta_{j}^{H} x_{i}$, respectively. In the process of gradient descent optimization, if the learning rate is set too large, it will easily lead to model overfitting. However, if the learning rate is set too small, it will reduce the model optimization speed. Therefore, this study adopts adaptive learning rate to solve this contradiction. The adaptive rule of learning rate is given in Formula (13).

$$
\Delta \eta(k)=\left\{\begin{array}{cc}
+a & \Delta E(k-1)<0 \\
-b \eta(k-1) & \Delta E(k-1)>0 \\
0 & \text { else }
\end{array}\right.
$$

where, $a$ and $b$ are step constants, $a>0, b>0, k$ represents the kth epoch. $\Delta E(k-1)$ represents the gradient value of the squared error function for the $k-1$ epochs of the BP neural network.

In this study, the initial learning rate is $\eta=0.015, \mathrm{a}=1.05, \mathrm{~b}=0.7$, the number of hidden layer neurons is 10 . Seventy percent of the 490 groups of sample data are used as training set: $15 \%$ as a test set, and the other $15 \%$ as a verification set. Mean Square Error (MSE) is used to determine the fitting accuracy of the model. Figure 8 shows the MSE change curve of the model. It can be seen from the figure that the MSE of the data fitting results of the training set, test set, and verification set changes with an increase in the number of model epochs. The training stopped after 25 epochs of the model, and the model accuracy reached the requirements. The MES of the validation set was minimized at the 19th epoch, with a value of 0.007289 .

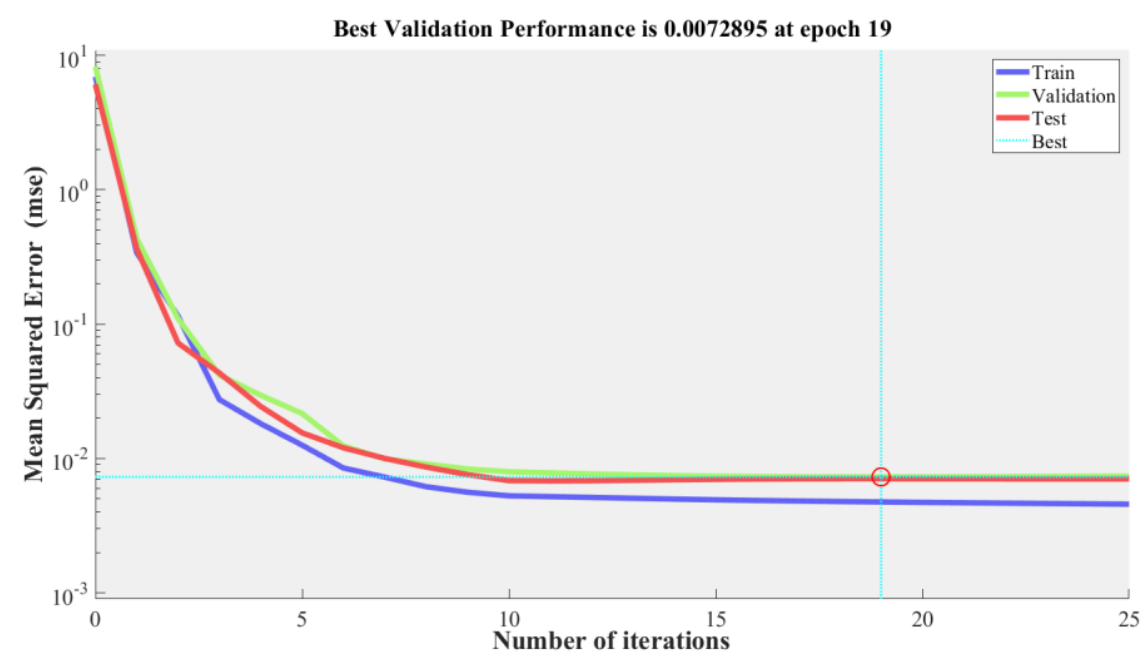

Figure 8. The MSE change curve of the model. 


\section{Modeling and Data Analysis}

\subsection{Multicollinearity Analysis}

In order to test whether the modeling method of coupling a PLS and BP neural network has an improvement for the accuracy of the model compared with the single modeling method, this study used Least Square Regression (LSR), Partial Least Square Regression (PLSR), and BP neural network (BPNN) for modeling based on the same data, respectively. The fitting scatter plots and residual histograms of four temperature error compensation models are shown in Figures 9 and 10.
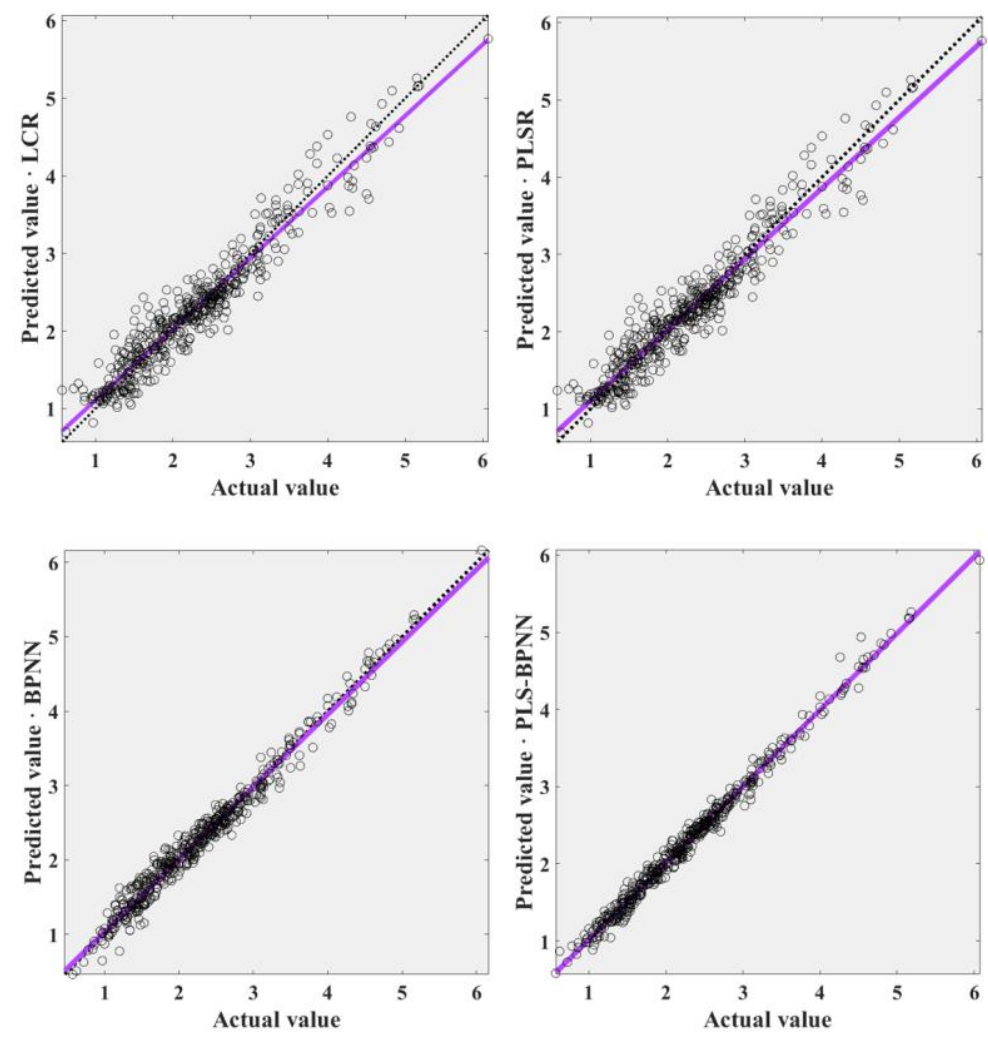

Figure 9. Scatter plot of fitting results of each model.

Figure 9 shows that the PLS-BPNN temperature error compensation model has the smallest relative error between the fitted values and the actual values, with most points falling on a straight line. The fits of the other models behave similarly, with more scattered points falling around the line. Besides, as shown in Figure 10, PLS-BPNN model also has the smallest residual distribution of -0.5 to 0.3 , while the LSR model has the largest residual range of -1.0 to 1.0 . This indicates that the PLS-BPNN model does significantly improve the temperature compensation accuracy.

In order to more clearly compare the fitting effects of the four models, the relative error, Root Mean Square Error (RMSE), and the temperature measurement results after applying the models were statistically analyzed, as shown in Table 2.

Table 2. Statistical table of fitting effect of each model.

\begin{tabular}{ccccccc}
\hline \multirow{2}{*}{ Model } & \multirow{2}{*}{$\begin{array}{c}\text { Number of } \\
\text { Components }\end{array}$} & \multirow{2}{*}{$\boldsymbol{R}^{2}$} & \multirow{2}{*}{$\mathbf{R M S E}$} & \multicolumn{3}{c}{ Relative Error/Count } \\
\cline { 5 - 7 } & & & & $<\mathbf{0 . 1}{ }^{\circ} \mathbf{C}$ & $\mathbf{0 . 1}{ }^{\circ} \mathbf{C} \sim \mathbf{0 . 3}{ }^{\circ} \mathbf{C}$ & $>\mathbf{0 . 3}{ }^{\circ} \mathbf{C}$ \\
\hline LSR & 3 & 0.96079 & 0.242418341 & 162 & 221 & 107 \\
PLSR & 6 & 0.97542 & 0.192571607 & 180 & 264 & 46 \\
BPNN & 3 & 0.98915 & 0.129683998 & 272 & 208 & 10 \\
PLS-BPNN & 0.99377 & 0.092084235 & 372 & 116 & 2 \\
\hline
\end{tabular}



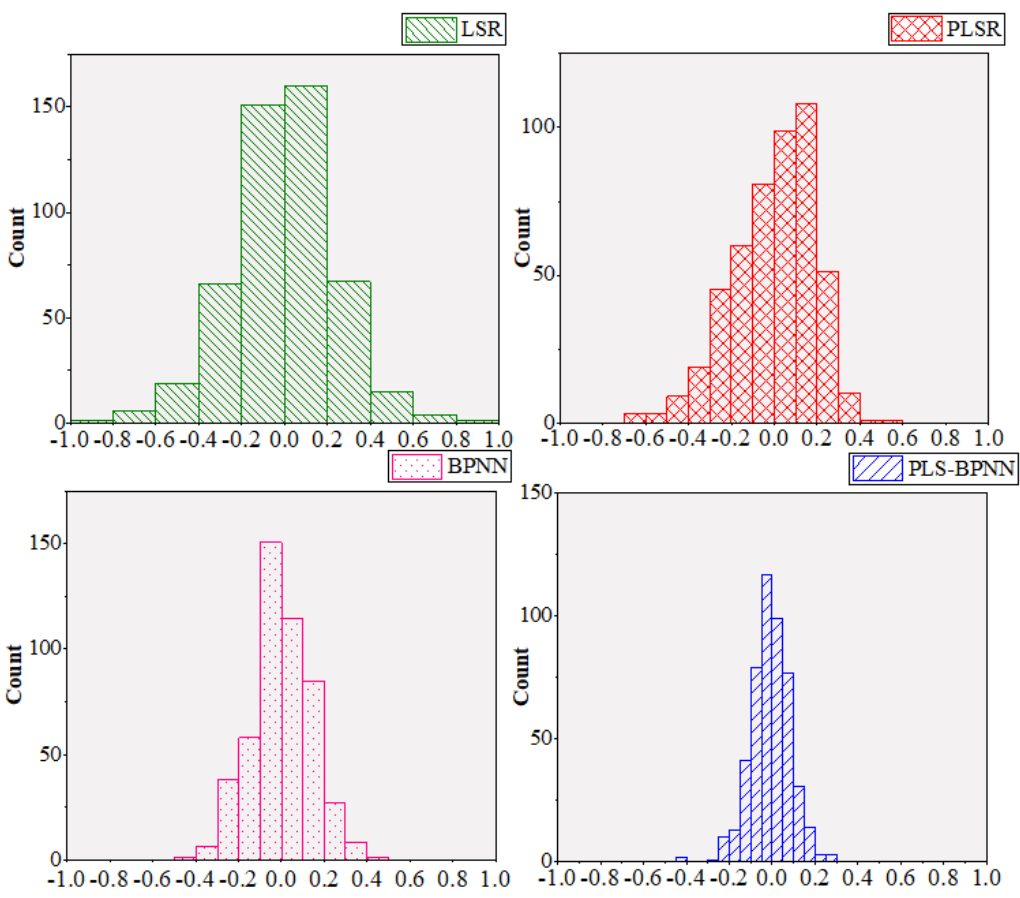

Figure 10. The residual histogram of each model.

Table 2 shows that the number of relative errors greater than $0.3{ }^{\circ} \mathrm{C}$ in the fitted data results of the LSR, PLSR, and BPNN models are 107, 46, and 16, respectively, while only two of the fitted results of the PLS-BPNN model have such a large error, and more than $75 \%$ of the fitted data have an error less than $0.1{ }^{\circ} \mathrm{C}$. The $R^{2}$ of PLS-BPNN model is 0.99377 , and the RMSE is about 0.092 , indicating that more than $99 \%$ of the total error of the smart helmet temperature measurement system can be explained by the dependence between temperature error and various influencing factors. Less than $1 \%$ is influenced by random factors. The $R^{2}$ of the LCR, PLSR, and BPNN models are all lower than that of the PLS-BPNN model, and the RMSE of all three models is also higher than that of the PLS-BPNN model, indicating that the PLS-BPNN temperature error compensation model is a better fit than the other three models.

\subsection{Infrared Temperature Measurement Compensation Test}

In order to further verify the effectiveness of PLS-BPNN temperature error compensation model in practical engineering applications, 24 groups (as shown in Table 3) of test data were obtained using self-developed smart helmets in this study. The data was obtained in the same manner as the data used for modeling.

As can be seen from Table 3, the accuracy of the temperature data collected directly by the smart helmet can hardly meet the needs for body temperature detection, and the relative average error reaches $2.80^{\circ} \mathrm{C}$, and the RMSE is 1.052. Then, the temperature error compensation was calculated using the PLS-BPNN model. After using the PLS-BPNN model to compensate the calculation, the relative average error is reduced to $0.055{ }^{\circ} \mathrm{C}$, and the RMSE is also reduced to 0.0671 . Figure 11 shows the relative temperature errors before and after compensation.

From Figure 11, it can be seen that, after using the PLS-BPNN model, the relative error range of the infrared temperature measurement results is $0.005 \sim 0.143{ }^{\circ} \mathrm{C}$, and the measurement accuracy has been significantly improved to meet the actual management needs of the construction site. 
Table 3. Test data used to validate the model.

\begin{tabular}{|c|c|c|c|c|c|c|}
\hline $\begin{array}{c}\text { Measured } \\
\text { Temperature } \\
\left({ }^{\circ} \mathrm{C}\right)\end{array}$ & $\begin{array}{c}\text { Ambient } \\
\text { Temperature } \\
\left({ }^{\circ} \mathrm{C}\right)\end{array}$ & $\begin{array}{c}\text { Ambient } \\
\text { Humidity } \\
(\%)\end{array}$ & $\begin{array}{c}\text { Temperature } \\
\text { Inside Helmet } \\
\left({ }^{\circ} \mathrm{C}\right)\end{array}$ & $\begin{array}{c}\text { Humidity } \\
\text { Inside Helmet } \\
(\%)\end{array}$ & $\begin{array}{l}\text { Wind Speed } \\
\qquad(\mathrm{m} / \mathrm{s})\end{array}$ & $\begin{array}{c}\text { Temperature Error } \\
\left({ }^{\circ} \mathrm{C}\right)\end{array}$ \\
\hline 33.05 & 26.41 & 71.75 & 28.79 & 70.86 & 3.65 & 3.44 \\
\hline 33.12 & 26.35 & 42.95 & 24.04 & 49.26 & 1.45 & 3.49 \\
\hline 32.47 & 27.70 & 47.09 & 24.22 & 44.09 & 1.99 & 4.32 \\
\hline 33.51 & 29.07 & 46.55 & 28.79 & 48.14 & 0.38 & 3.10 \\
\hline 32.32 & 28.14 & 40.6 & 24.81 & 48.55 & 1.34 & 4.30 \\
\hline 32.71 & 26.98 & 42.69 & 24.20 & 50.00 & 1.01 & 3.86 \\
\hline 32.74 & 27.55 & 42.69 & 24.58 & 50.00 & 2.71 & 3.86 \\
\hline 32.75 & 27.03 & 46.78 & 24.39 & 46.3 & 2.75 & 4.05 \\
\hline 32.77 & 27.46 & 46.94 & 24.44 & 47.16 & 3.11 & 4.02 \\
\hline 34.92 & 23.56 & 60.39 & 28.97 & 53.82 & 0 & 1.96 \\
\hline 33.66 & 25.80 & 71.26 & 29.05 & 71.56 & 2.99 & 2.82 \\
\hline 33.73 & 26.46 & 68.73 & 27.52 & 68.64 & 0 & 3.04 \\
\hline 34.65 & 24.76 & 78.36 & 27.83 & 70.49 & 0 & 1.76 \\
\hline 34.66 & 32.94 & 56.11 & 30.69 & 67.29 & 1.46 & 2.14 \\
\hline 33.67 & 26.46 & 48.72 & 27.36 & 46.05 & 2.83 & 3.13 \\
\hline 34.66 & 24.49 & 58.48 & 29.79 & 57.46 & 1.39 & 2.04 \\
\hline 34.63 & 23.71 & 60.16 & 28.22 & 53.56 & 0 & 2.24 \\
\hline 34.65 & 32.01 & 56.23 & 30.63 & 63.02 & 0.19 & 2.34 \\
\hline 34.67 & 24.67 & 74.39 & 27.87 & 73.96 & 0 & 1.83 \\
\hline 35.12 & 24.35 & 81.18 & 28.35 & 70.19 & 0 & 1.49 \\
\hline 35.54 & 24.56 & 59.59 & 29.50 & 56.59 & 0 & 1.42 \\
\hline 36.24 & 34.79 & 40.16 & 32.48 & 36.00 & 1.90 & 0.96 \\
\hline 31.88 & 27.49 & 44.32 & 24.58 & 51.26 & 2.88 & 4.62 \\
\hline 33.80 & 25.27 & 81.39 & 27.40 & 73.73 & 0 & 2.70 \\
\hline
\end{tabular}

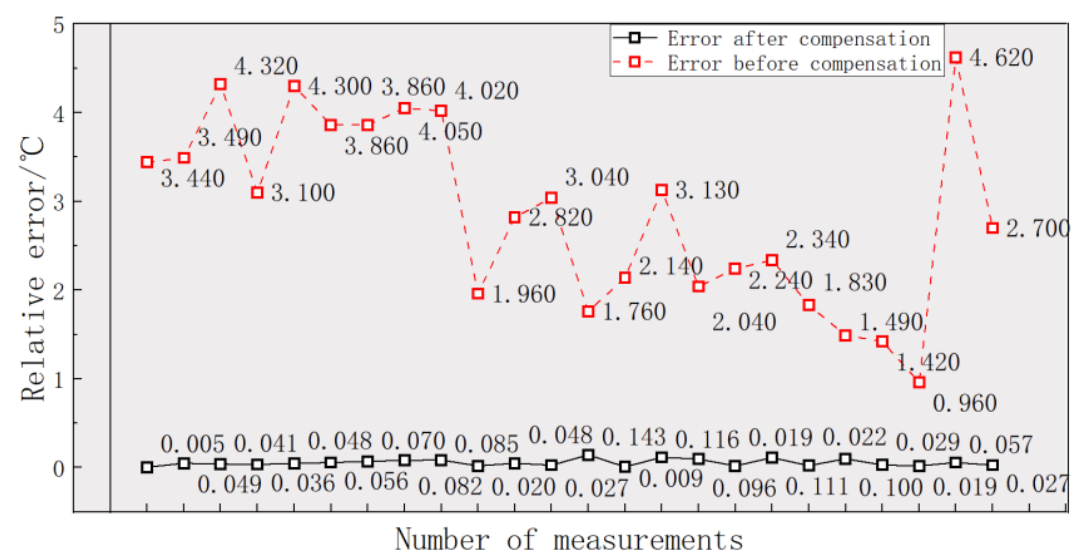

Figure 11. Temperature error before and after compensation of PLS-BPNN model.

The above test results show that the PLS-BPNN temperature error compensation model can better compensate the error between the measured value of the infrared temperature measurement system of the smart helmet and the actual body temperature, which further reflects the advantages of the coupled model in dealing with the multiple correlation and nonlinearity between the independent variables. At the same time, with the help of the PLS-BPNN model, the smart helmet equipped with an infrared temperature sensor can also play the role of human body temperature tracking and monitoring, assisting in epidemic prevention and control in the actual construction management.

\section{Conclusions}

For the problem that there may be a large difference between the temperature measured by the infrared temperature measurement system and the actual body temperature of the smart helmet, this study developed a smart helmet equipped with an infrared tem- 
perature sensor and designed a simulated construction experiment to collect temperature data and data of various influencing factors that may affect the accuracy of temperature measurement in indoor and outdoor operating environments, including ambient temperature, ambient humidity, temperature inside the helmet, humidity inside the helmet, and ambient wind speed. After that, a PLS-BPNN temperature error compensation model was established based on the experimental data to correct the temperature measurement results of the smart helmet. The model uses the PLS method to extract the principal components of the temperature influencing factors and uses them as input variables to effectively eliminate the effect of multicollinearity between input variables. Meanwhile, the advantage of a BP neural network in nonlinear approximation was used to solve the nonlinear problem of the coupled model.

In addition, this study also compared the temperature compensation effect of PLSBPNN model with LSR, PLSR, and BPNN models, and the results showed that the PLSBPNN model had a higher accuracy and reliability. For the experimental data collected in this study, the relative error range of infrared body temperature detection was only $0.005-0.143{ }^{\circ} \mathrm{C}$ after the compensation calculation of the PLS-BPNN model, which fully meets the requirements of personnel temperature monitoring in construction site management. That is, with the assistance of the PLS-BPNN temperature compensation model, the smart helmet equipped with infrared temperature sensor has good application prospects in construction personnel health management.

In the research process, it was found that, if the multivariate statistical analysis theory and neural network are well connected, the accuracy and efficiency of the model can be greatly improved. Therefore, this provides a new horizon for future research to solve similar problems.

In addition to this, the proposed research method has several limitations. Most of the temperature data used for modeling by this model are in the normal range, and there is a lack of data of people with fever, which may lead to the poor compensation effect of the model for the partial error of hyperthermia (temperature greater than $37.5^{\circ} \mathrm{C}$ ). Collecting more data can result in more accurate results. In future research, experimental data of febrile patients can be collected to improve the accuracy and generalizability of the model. Since neural network algorithms play a crucial role in the performance of the model, using other neural network algorithms or using different activation functions in the same neural network algorithm may help improve the accuracy and efficiency of our proposed method, and future research can try to use different neural network algorithms to improve the performance of the model.

Author Contributions: Funding acquisition, conceptualization and methodology, L.L.; device development, H.C.; experiments, data analysis and writing—original draft preparation, J.Y.; writingreview and editing, L.L. and M.P. All authors have read and agreed to the published version of the manuscript.

Funding: This research was supported by the National Natural Science Foundation of Shanghai, China (Funding Agency Project No. 19ZR1418800). The authors are grateful for their financial support.

Institutional Review Board Statement: Not applicable.

Informed Consent Statement: Not applicable.

Data Availability Statement: Data is contained within the article.

Acknowledgments: The authors would like to acknowledge the support and facilities provided by the Department of Civil Engineering, School of Mechanics and Engineering Science at Shanghai University to carry out the research. The assistance provided by Shuying Luo, Runzhi Yang, Yu Lu and Baihao Fang in conducting the simulated construction experiment is gratefully acknowledged by the authors.

Conflicts of Interest: The authors declare no conflict of interest. 


\section{References}

1. Paules, C.I.; Marston, H.D.; Fauci, A.S. Coronavirus Infections-More Than Just the Common Cold. J. Am. Med Assoc. 2020, 323, 707-708. [CrossRef]

2. Lippi, G.; Sanchis-Gomar, F.; Henry, B.M. COVID-19: Unravelling the clinical progression of nature's virtually perfect biological weapon. Ann. Transl. Med. 2020, 8, 693. [CrossRef] [PubMed]

3. Viswanathan, M.; Kahwati, L.; Jahn, B.; Giger, K.; Gartlehner, G. Universal screening for SARS-CoV-2 infection: A rapid review. Cochrane Database Syst. Rev. Online 2020, 9. [CrossRef]

4. Zhang, J.; Liu, S.; Zhu, B. Fever screening methods in public places during the COVID-19 pandemic. J. Hosp. Infect. 2021, 109, 123-124. [CrossRef] [PubMed]

5. Lippi, G.; Mattiuzzi, C.; Henry, B. Is Body Temperature Mass Screening a Reliable and Safe Option for Preventing COVID-19 Spread? SSRN Electron. J. 2021. [CrossRef]

6. Kodam, S.; Bharathgoud, N.; Ramachandran, H. A review on smart wearable devices for soldier safety during battlefield using WSN technology. Mater. Today Proc. 2020, 33, 4578-4585. [CrossRef]

7. Sawant, P.; Godse, S.; Thigale, V.; Kasar, K. Arduino Based Smart Helmet for Coal Mine Safety. In Proceedings of the 2nd International Conference on Communication \& Information Processing (ICCIP) 2020, Pune, India, 8 July 2020.

8. Yong, J.A.; Kang, M.; Lee, T.G. Study on Remedies of Convergence Design for Personalized Fire Helmets. J. Korean Soc. Precis. Eng. 2016, 33, 371-376.

9. Altamura, A.; Inchingolo, F.; Mevoli, G.; Boccadoro, P. SAFE: Smart helmet for Advanced Factory Environment. Internet Technol. Lett. 2019, 2, e86. [CrossRef]

10. Aliyev, A.; Zhou, B.P. HeadgearX: A connected smart helmet for construction sites. In Proceedings of the 2020 ACM International Joint Conference on Pervasive and Ubiquitous Computing and Proceedings of the 2020 ACM International Symposium on Wearable Computers, New York, NY, USA, 14 September 2020.

11. Dell'Isola, G.B.; Cosentini, E.; Canale, L.; Ficco, G.; Dell'Isola, M. Noncontact Body Temperature Measurement: Uncertainty Evaluation and Screening Decision Rule to Prevent the Spread of COVID-19. Sensors 2021, 21, 346. [CrossRef] [PubMed]

12. Tanaka, Y.; Matsunaga, D.; Tajima, T.; Seyama, M. Skin-attachable Sensor for Core Body Temperature Monitoring. IEEE Sens. J. 2021, 14, 1.

13. Xu, K.; Zhao, L.; Yuan, Y. Measurement error analysis and compensation experiment research for medicinal infrared thermometer. Electron. Meas. Technol. 2014, 37, 104-118.

14. Guo, Z.; Dai, S.; Liu, Z.; You, C.; Cheng, Y.; Yu, L. Research on application of polynomial fitting technique in rotary kiln infrared temperature measurement system. Infrared Phys. Technol. 2016, 79, 160-164. [CrossRef]

15. Wei, S.; Qin, W.; Han, L.; Cheng, F. The research on compensation algorithm of infrared temperature measurement based on intelligent sensors. Clust. Comput. 2019, 22, 6091-6100. [CrossRef]

16. Shajkofci, A. Correction of human forehead temperature variations measured by non-contact infrared thermometer. IEEE Sens. J. 2021, 99, 1. [CrossRef]

17. Ai, H.; Hu, M.; Liu, H.; Yu, H.; Wang, G.; Wang, W. Development of ear cavity infrared thermometer based on thermal radiation. Sens. Microsyst. 2020, 39, 94-96.

18. Pan, D.; Jiang, Z.; Maldague, X.; Gui, W. Research on the Influence of Multiple Interference Factors on Infrared Temperature Measurement. IEEE Sens. J. 2021, 21, 10546-10555.

19. Ning, B.; Wu, Y. Research on Non-Contact Infrared Temperature Measurement. In Proceedings of the 2010 International Conference on Computational Intelligence and Software Engineering, Wuhan, China, 10-12 December 2010.

20. Shu, Q.; Dai, S.; Nie, H.; Yi, W. Dynamic temperature compensation model based on nonuniform temperature field change. Infrared Phys. Technol. 2019, 101, 25-31. [CrossRef]

21. Church, J.S.; Hegadoren, P.R.; Paetkau, M.J.; Miller, C.C.; Regev-Shoshani, G.; Schaefer, A.L.; Schwartzkopf-Genswein, K.S. Influence of environmental factors on infrared eye temperature measurements in cattle. Res. Vet. Sci. 2014, 96, 220-226. [CrossRef] [PubMed]

22. Kamada, Y.; Miyamoto, N.; Yamakage, M.; Tsujiguchi, N.; Namiki, A. Utility of an infrared ear thermometer as an intraoperative core temperature monitor. Masui Jpn. J. Anesthesiol. 1999, 48, 1121.

23. Gonzalez, A.J.; Teller, C.; Andersen, S.L.; Jensen, F.B. Influence of body temperature on the development of fatigue during prolonged exercise in the heat. J. Appl. Physiol. 1999, 86, 1032-1039. [CrossRef]

24. Campa, F.; Gatterer, H.; Lukaski, H.; Toselli, S. Stabilizing Bioimpedance-Vector-Analysis Measures With a 10-Minute Cold Shower After Running Exercise to Enable Assessment of Body Hydration. Int. J. Sports Physiol. Perform. 2019, 14, 1006-1009. [CrossRef]

25. Emerson, D.M.; Chen, S.C.; Kelly, M.R.; Parnell, B. Non-steroidal anti-inflammatory drugs on core body temperature during exercise: A systematic review. J. Exerc. Sci. Fit. JESF 2021, 19, 127-133. [CrossRef]

26. Werth, J.; Sigman, M.S. Linear Regression Model Development for Analysis of Asymmetric Copper Bisoxazoline Catalysis. ACS Catal. 2021, 11, 3916-3922. [CrossRef] [PubMed]

27. Cheng, J. Residential land leasing and price under public land ownership. J. Urban Plan. Dev. 2021, 147, 05021009. [CrossRef]

28. Cheng, J. Analysis of commercial land leasing of the district governments of Beijing in China. Land Use Policy 2021, $100,104881$. [CrossRef] 
29. Cheng, J. Data analysis of the factors influencing the industrial land leasing in Shanghai based on mathematical models. Math. Probl. Eng. 2020, 2020, 9346863. [CrossRef]

30. Cheng, J. Mathematical Models and Data Analysis of Residential Land Leasing Behavior of District Governments of Beijing in China. Mathematics 2021, 9, 2314. [CrossRef]

31. Mancini, M.; Taavitsainen, V.; Toscano, G. Comparative study between Partial Least Squares and Rational function Ridge Regression models for the prediction of moisture content of woodchip samples using a handheld spectrophotometer. J. Chemom. 2021, 35, e3337. [CrossRef]

32. Panzone, L.; Ulph, A.; Areal, F.; Grippo, V. A ridge regression approach to estimate the relationship between landfill taxation and waste collection and disposal in England. Waste Manag. 2021, 129, 95-110. [CrossRef] [PubMed]

33. Ataman, M.G.; Saryer, G. Predicting waiting and treatment times in emergency departments using ordinal logistic regression models. Am. J. Emerg. Med. 2021, 46, 45-50. [CrossRef] [PubMed]

34. Cheng, J. Analyzing the factors influencing the choice of the government on leasing different types of land uses: Evidence from Shanghai of China. Land Use Policy 2020, 90, 104303. [CrossRef]

35. He, S.; Wang, Y. A Modified APLS for Key Performance Indicator-Related Diagnosis in Case of Outliers. In Proceedings of the Chinese Automation Congress (CAC), Jinan, China, 20-22 October 2017.

36. Zhang, J.; Lou, Y. Water Level Prediction Based on Improved Grey RBF Neural Network Model. In Proceedings of the 2016 IEEE Advanced Information Management, Communicates, Electronic and Automation Control Conference (IMCEC), Xi'an, China, 3-5 October 2016.

37. Herawati, N.; Nisa, K.; Setiawan, E. Regularized Multiple Regression Methods to Deal with Severe Multicollinearity. Int. J. Stat. Appl. 2018, 8, 167-172.

38. Evans, M. A partial least squares solution to the problem of multicollinearity when predicting the high temperature properties of 1Cr-1Mo-0.25V steel using parametric models. J. Mater. Sci. 2012, 47, 2712-2724. [CrossRef]

39. Cai, T.; Ju, C.; Yang, X. Comparison of Ridge Regression and Partial Least Squares Regression for Estimating Above-Ground Biomass with Landsat Images and Terrain Data in Mu Us Sandy Land, China. Arid. Land Res. Manag. 2009, 23, 248-261. [CrossRef]

40. Polat, E.; Gunay, S. The comparison of partial least squares regression, principal component regression and ridge regression with multiple linear regression for predicting pm10 concentration level based on meteorological parameters. J. Data Ence 2015, 13, 663-692.

41. Fita, K.; Arief, W. Principal Component Analysis (PCA) untuk Mengatasi Multikolinieritas terhadap Faktor Angka Kejadian Pneumonia Balita di Jawa Timur Tahun 2014. J. Biom. Dan Kependud. 2018, 6, 89.

42. Khedhe, L.; Ramirez, J.; Gorriz, J.M.; Brahim, A.; Segovia, F. Early diagnosis of Alzheimers disease based on partialleast squares, principal component analysis and support vector machine using segmented MRI images. Neurocomputing 2015, 151, 139-150. [CrossRef]

43. Li, M.; Verma, B. An Improved RBF Neural Network Approach to Nonlinear Curve Fitting. Adv. Comput. Intell. 2015, 9095, 262-275.

44. Wang, G.; Wu, J.; Yin, S.; Yu, L.; Wang, J. Comparison between BP Neural Network and Multiple Linear Regression Method. In Proceedings of the Information Computing and Applications-First International Conference, ICICA 2010, Tangshan, China, 15-18 October 2010.

45. An, Y.; Wang, X.; Qu, Z.; Liao, T.; Wu, L.; Nan, Z. Stable temperature calibration method of fiber Bragg grating based on radial basis function neural network. Opt. Eng. 2019, 58, 1. [CrossRef]

46. Wu, W.; Wang, J.; Cheng, M.; Li, Z. Convergence analysis of online gradient method for BP neural networks. Neural Netw. 2019, 24, 91-98. [CrossRef]

47. Sun, Y.; Yang, H. The Forecasting Method for the Furnace Bottom Temperature and Carbon Content of Submerged Arc Furnace Based on Improved BP Neural Network. In Proceedings of the International Conference on Computer, Mechatronics, Control and Electronic Engineering, Changchun, China, 24-26 August 2010.

48. Qiu, J.W.; Liu, Z.G.; Zhou, L.; Qin, R.X. Prediction Model of Gas Quantity Emitted from Coal Face Based on PCA-GA-BP Neural Network and Its Application. J. Power Technol. 2017, 97, 169-178.

49. Habshah, M.; Saroje, S.; Sohel, R. Collinearity diagnostics of binary logistic regression model. J. Interdiscip. Math. 2010, 13, $253-267$.

50. Aylin, A. Multicollinearity. Wiley Interdiscip. Rev. Comput. Stat. 2010, 2, 370-374. [CrossRef]

51. Adler, J.; Parmryd, I. Quantifying colocalization by correlation: The Pearson correlation coefficient is superior to the Mander's overlap coefficient. Cytom. Part A 2010, 77, 33-42. [CrossRef]

52. Gilbert, C.L. The Diagnosis of Multicollinearity. Oxf. Bull. Econ. Stat. 2010, 40, 87-91. [CrossRef]

53. O'brien, R.M. A Caution Regarding Rules of Thumb for Variance Inflation Factors. Qual. Quant. 2007, 41, 673-690. [CrossRef]

54. Wold, S.; Sjöström, M. Lennart Eriksson, PLS-regression: A basic tool of chemometrics. Chemom. Intell. Lab. Syst. 2001, 58, 109-130. [CrossRef]

55. Buscema, M. Back Propagation Neural Networks. Subst. Use Misuse 1998, 33, 233-270. [CrossRef]

56. Torrontegui, E.; Garcia-Ripoll, J. Universal quantum perceptron as efficient unitary approximators. Europhys. Lett. 2018, 125, 30004. [CrossRef] 
57. Ilunga, M.; Stephenson, D. Infilling streamflow data using feed-forward back-propagation (BP) artificial neural networks: Application of standard BP and pseudo Mac Laurin power series BP techniques. Water SA 2005, 31, 171-176. [CrossRef]

58. Langer, S. Approximating smooth functions by deep neural networks with sigmoid activation function. J. Multivar. Anal. 2021, 182, 104696. [CrossRef] 